http://jmscr.igmpublication.org/home/ ISSN (e)-2347-176x ISSN (p) 2455-0450 crossref DOI: https://dx.doi.org/10.18535/jmscr/v7i10.139

Journal Of Medical Science And Clinical Research

\title{
Neonatal Hearing Screening Programme - In a Rural Based Tertiary Care Centre
}

\author{
Authors \\ Dr Ruta Shanmugam ${ }^{1}$, Dr Viveknarayan.G', Dr Saravanan ${ }^{3}$, Dr Balaji Swaminathan ${ }^{4}$, \\ Dr V.U.Shanmugam ${ }^{5}$, Dr Prem Nivas ${ }^{6}$ \\ ${ }^{1}$ Professor, Dept of ENT, RMMCH, Annamalai University, Chidambaram \\ ${ }^{2}$ Post Graduate, Dept of ENT, RMMCH, Annamalai University, Chidambaram \\ ${ }^{3}$ Professor, Dept of Paediatrics, RMMCH, Annamalai University, Chidambaram \\ ${ }^{4}$ HOD, Dept of ENT, RMMCH, Annamalai University, Chidambaram \\ ${ }^{5}$ Professor, Dept of ENT, RMMCH, Annamalai University, Chidambaram \\ ${ }^{6}$ Assistant Professor, Dept of ENT, RMMCH, Annamalai University, Chidambaram
}

\begin{abstract}
Introduction: Hearing loss and deafness are global issues that affect at least 278 million people worldwide ${ }^{1}$. The incidence of hearing impairment in India is 1-6 per thousand newborns screened ${ }^{2}$.

Objective: To evaluate the incidence of hearing impairment among high risk neonates in a rural based tertiary care hospital. To detect permanent hearing impairment of moderate to severe degree, at the earliest possible time. To provide appropriate intervention (medical/surgical/rehabilitation) following the detection of a permanent hearing impairment.

Methods and Materials: It is a descriptive, observational and interventional study conducted over a span of 2 years.

Inclusion Criteria: All high risk neonates born in a rural based tertiary care hospital during the study period.

Exclusion Criteria: Cases of congenital meatal atresia were excluded from the study.

Method of Study: All high risk neonates born and high risk neonates admitted during the study period have undergone hearing assessment using transient evoked otoacoustic emissions (TEOAE), as the first level of hearing screening.

Results: 315 at risk neonates were screened and 3 were detected to have hearing impairment which is an incidence of 9.5 per 1000 screened.

Conclusion: While it may not be technically feasible to screen all newborns in a rural setting like ours, screening must definitely be made mandatory for all high risk neonates using otoacoustic emissions as early as possible in order to preserve the deepest, most humanizing philosophical sense man possesses, that is, hearing.
\end{abstract}

Keywords: High risk newborns, Transient evoked otoacoustic emissions, Hearing impairment.

\section{Introduction}

Hearing is the deepest, most humanizing philosophical sense man possesses. Hearing loss and deafness are global issues that affect at least 278 million people worldwide. Two third of these people live in developing countries. ${ }^{1}$ The 
incidence of hearing impairment in India is 1-6 per thousand newborns screened. ${ }^{2}$ It is well recognised that unidentified hearing impairment can adversely affect optimal speech and language development. Over 5\% of the world's population has disabling hearing loss of which 10\% (32 million) are children. ${ }^{2}$ The world health organization has quoted that in infants and children with hearing loss, early identification and management through infant hearing screening programmes can improve the linguistic and educational outcomes for each child. Most of the developed countries have successfully finalised universal neonatal hearing screening programmes, however in India, such programmes are still nascent. Financial and social constraints have augmented its nationwide application.

Otoacoustic emission (OAE) will be used in this study as it is very sensitive, noninvasive, cost and time effective making it an ideal screening method. ${ }^{3}$ OAEs are used to assess the structural and functional measurements of the response of outer hair cells of the cochlea to acoustic stimuli. They serve as a fast objective screening test for normal cochlear function. ${ }^{4}$

Transient evoked otoacoustic emissions (TEOAE) has a sensitivity as high as $95 \%-98 \%$ and a specificity of $80 \%-85 \% .^{5}$ Hence, the current study is planned to find the incidence of hearing impairment in high risk newborns in a rural based tertiary care centre.

\section{High Risk Infants}

Joint committee of Infant hearing guidelines for high risk criteria. ${ }^{6}$

1) Caregiver concern regarding hearing, speech, language, or developmental delay.

2) Family history of permanent childhood hearing loss.

3) Neonatal intensive care of more than 5 days or any of the following regardless of length of stay: assisted ventilation, exposure to ototoxic medications (gentimycin and tobramycin) or loop diuretics like furosemide and hyperbilirubinemia that requires exchange transfusion.

4) In utero infections, such as CMV, herpes, rubella, syphilis, and toxoplasmosis.

5) Craniofacial anomalies, including those that involve the pinna, ear canal, ear tags, ear pits, and temporal bone anomalies.

6) Physical findings, such as white forelock, those are associated with a syndrome known to include a sensorineural or permanent conductive hearing loss.

7) Syndromes associated with hearing loss or progressive or late-onset hearing loss

8) Neurodegenerative disorders

9) Culture-positive postnatal infections associated with sensorineural hearing loss, including confirmed bacterial and viral (especially herpes viruses and varicella) meningitis.

10) Head trauma, especially basal skull/temporal bone fracture that requires hospitalization.

11) Chemotherapy.

\section{Materials and Methods Study Design}

It is a descriptive, observational and interventional study conducted over a span of 2years from November 2017 to October 2019.

\section{Source of Data}

Study conducted among the high risk newborns at Rajah Muthiah Medical College Hospital.

\section{Study Period}

November 2017 to October 2019.

\section{Study Population}

Total number of high risk newborn admitted at Rajah Muthiah Medical College Hospital during the period of 2017-2019.

\section{Inclusion Criteria}

All high risk neonates admitted in Rajah Muthiah Medical College Hospital during the study period 2017-2019 were screened for hearing loss prior to discharge from the hospital.

\section{Exclusion Criteria}

Cases of congenital meatal atresia were excluded from the study. 


\section{Method of Study}

- After obtaining ethical committee approval, study was started in Rajah Muthiah Medical College Hospital. Parents/grandparents of the neonates were informed, counselled and written consent was obtained about the study and neonatal hearing screening programme.

- Each participant's demographic details along with their perinatal and postnatal data were taken, and ear, nose, and throat examination was done. Details were filled in the participant's proforma.

- All high risk neonates born during the study period in the Rajah Muthiah Medical College Hospital underwent hearing assessment using transient evoked otoacoustic emissions (TEOAE), as the first level of hearing screening .Neonates who failed the first level of hearing screening were subjected to a second level of hearing screening after 10 days by performing $2^{\text {nd }}$ TEOAE test.

- This was done in the department of otorhinolaryngology and head and neck surgery at Rajah Muthiah Medical College Hospital using a MADSEN AccuScreen OAE \& ABR Screener, which is a completely automated analysis system that gives a "PASS" or "REFER" result.

- "PASS" - suggest that the neonate has no hearing impairment in the specific frequency tested and "REFER" - suggest a possibility of a sensorineural hearing loss or indicates requirement of further diagnostic hearing evaluation.

- Neonates who did not pass the $2^{\text {nd }}$ TEOAE test underwent confirmatory test brain stem evoked responses (BERA) at the age of 3months.
METHOD OF STUDY

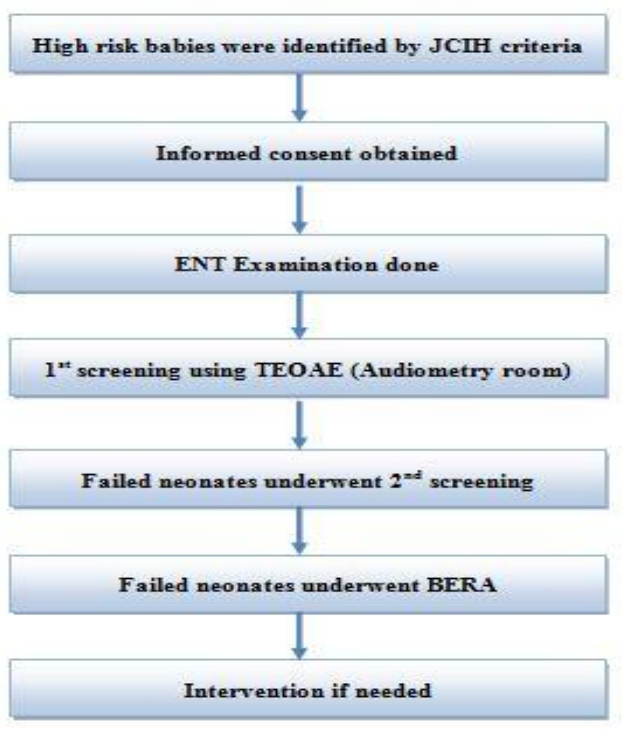

\section{Observation and Results}

Table - 1: Sex

\begin{tabular}{|l|c|c|}
\hline & No of Babies & Percentage \\
\hline Male & 156 & 49.5 \\
\hline Female & 159 & 50.5 \\
\hline Total & 315 & 100.0 \\
\hline
\end{tabular}

Table - 2: High Risk Factor

\begin{tabular}{|l|c|c|}
\hline & $\begin{array}{c}\text { No of } \\
\text { babies }\end{array}$ & Percentage \\
\hline Birth asphyxia / Low APGAR & 233 & 74.0 \\
\hline Craniofacial anomalies & 10 & 3.2 \\
\hline Family history of deafness & 12 & 3.8 \\
\hline Hyperbilirubinemia & 2 & 0.6 \\
\hline Torch infection & 2 & .6 \\
\hline VLBW & 56 & 17.8 \\
\hline Total & 315 & 100.0 \\
\hline
\end{tabular}

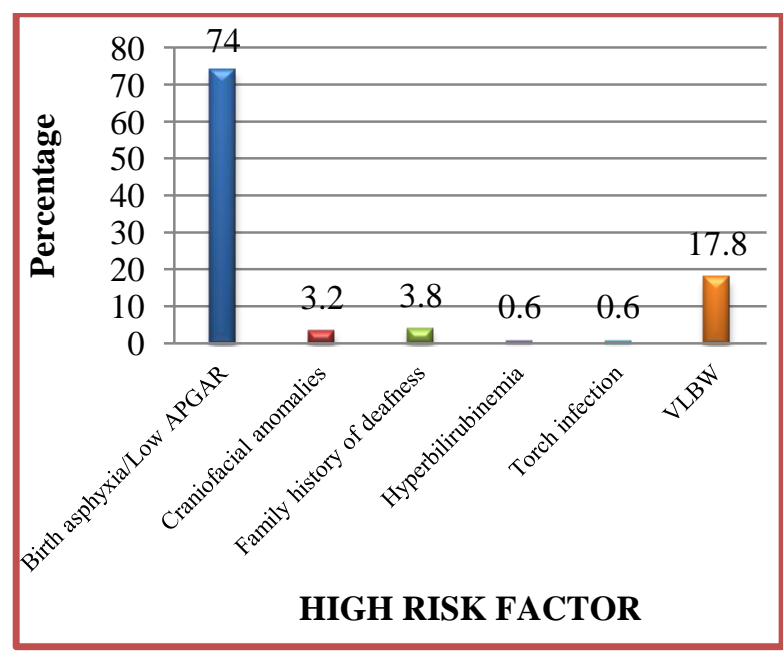


The most common high risk factor encountered in our study was birth asphyxia with low APGAR $(74 \%)$

Table - 3: OAE 1

\begin{tabular}{|l|c|c|}
\hline Result & No of babies & Percentage \\
\hline Pass & 231 & 73.3 \\
\hline Refer & 84 & 26.7 \\
\hline Total & 315 & 100.0 \\
\hline
\end{tabular}

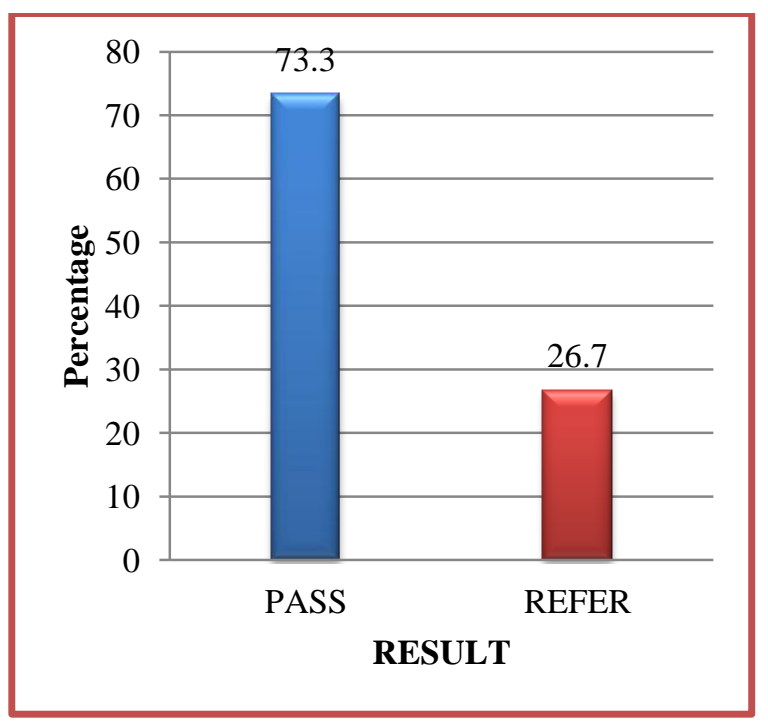

Out of 315 babies screened using OAE, 231 babies $(73.3 \%)$ passed the test on the first occasion. 84 babies had to undergo second OAE.

Table - 4: High Risk Factor * OAE 1 Cross tabulation

\begin{tabular}{|l|c|c|c|}
\hline \multirow{2}{*}{ High risk factor } & \multicolumn{2}{|c|}{ OAE 1 } & \multirow{2}{*}{ Total } \\
\cline { 2 - 3 } & Pass & Refer & \\
\hline $\begin{array}{l}\text { Birth asphyxia } \\
\text { Low APGAR }\end{array}$ & 175 & 58 & 233 \\
\hline $\begin{array}{l}\text { Craniofacial } \\
\text { anomalies }\end{array}$ & 7 & 3 & 10 \\
\hline $\begin{array}{l}\text { Family history of } \\
\text { deafness }\end{array}$ & 8 & 4 & 12 \\
\hline Hyperbilirubinemia & 2 & 0 & 2 \\
\hline Torch infection & 1 & 1 & 2 \\
\hline VLBW & 38 & 18 & 56 \\
\hline Total & 231 & 84 & 315 \\
\hline
\end{tabular}

Table - 5: OAE 2

\begin{tabular}{|l|c|c|}
\hline OAE 2 & No of babies & Percentage \\
\hline Missed & 9 & 10.71 \\
\hline Pass & 63 & 75.0 \\
\hline Refer & 12 & 14.29 \\
\hline Total & 84 & 100.0 \\
\hline
\end{tabular}

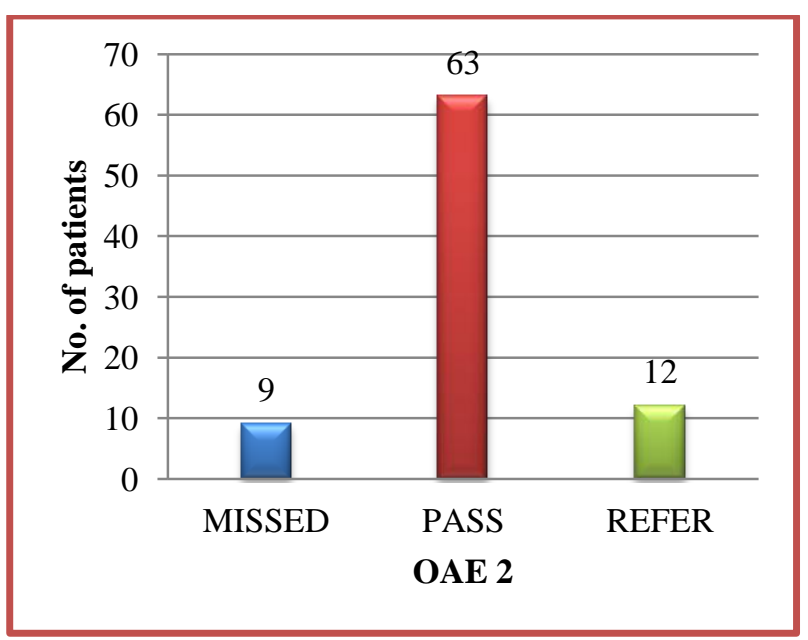

Of the 84 babies referred for $2^{\text {nd }}$ OAE, 63 babies passed the OAE test, 9 babies did not turn up for the $2^{\text {nd }} \mathrm{OAE}$ test and 12 babies did not pass the test.

Table - 6: High Risk Factor*OAE2

\begin{tabular}{|l|c|c|c|c|}
\hline \multirow{2}{*}{ High risk factor } & \multicolumn{3}{|c|}{ OAE 2 } & \multirow{2}{*}{ Total } \\
\cline { 2 - 5 } & Missed & Pass & Refer & \\
\hline Birth asphyxia & 5 & 49 & 4 & 58 \\
\hline $\begin{array}{l}\text { Craniofacial } \\
\text { anomalies }\end{array}$ & 0 & 2 & 1 & 3 \\
\hline $\begin{array}{l}\text { Family history of } \\
\text { deafness }\end{array}$ & 1 & 2 & 1 & 4 \\
\hline Torch infection & 0 & 1 & 0 & 1 \\
\hline VLBW & 3 & 9 & 6 & 18 \\
\hline Total & 9 & 63 & 12 & 84 \\
\hline
\end{tabular}

Table - 7: BERA

\begin{tabular}{|l|c|c|}
\hline BERA & No of babies & Percentage \\
\hline Hearing impairment & 3 & 25 \\
\hline Normal & 9 & 75 \\
\hline Total & 12 & 100.0 \\
\hline
\end{tabular}




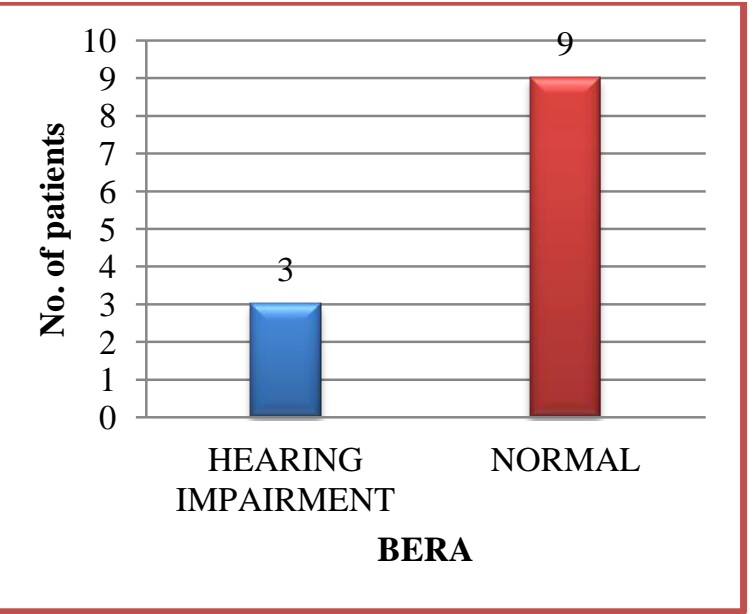

12 babies who failed $2^{\text {nd }}$ OAE underwent BERA.

Table - 8: High Risk Factor * BERA Cross tabulation

\begin{tabular}{|l|c|c|c|}
\hline \multirow{2}{*}{ High Risk Factor } & \multicolumn{2}{|c|}{ BERA } & \multirow{2}{*}{ Total } \\
\cline { 2 - 3 } & $\begin{array}{c}\text { Hearing } \\
\text { impairment }\end{array}$ & Normal & \\
\hline $\begin{array}{l}\text { Birth asphyxia } \\
\text { Low APGAR }\end{array}$ & 0 & 4 & 4 \\
\hline $\begin{array}{l}\text { Craniofacial } \\
\text { anomalies }\end{array}$ & 1 & 0 & 1 \\
\hline $\begin{array}{l}\text { Family history of } \\
\text { deafness }\end{array}$ & 1 & 0 & 1 \\
\hline VLBW & 1 & 5 & 6 \\
\hline Total & 3 & 9 & 12 \\
\hline
\end{tabular}

\section{Summary}

315 at risk neonates were screened over a period of two years in Rajah Muthiah Medical College Hospital to evaluate the incidence of hearing impairment in a rural based tertiary care centre. 156 were male babies $(49.5 \%$ and 159 were female babies $(50.5 \%)$. The most common high risk factor encountered was birth asphyxia/low APGAR (74\%), very low birth weight (17.8\%).

Of the 315 neonates screened, 294 passed the OAE test. 9 babies were lost for follow up. 12 babies underwent BERA test.

Among 12 babies in whom BERA was done, 3 babies had moderate to severe hearing impairment which accounts to an incidence of 9.5 per 1000 screened.

3 babies with hearing impairment were advised for cochlear implantation work up.

\section{Conclusion}

While it may not be technically feasible to screen all newborns in a rural setting like ours, hearing screening must definitely be made mandatory for all high risk neonates using otoacoustic emissions as early as possible to preserve the deepest, most humanising philosophical sense man possesses, that is, hearing.

Developing countries like India must take initiatives to implement newborn hearing screening programme at the level of district hospitals and primary health centres.

\section{References}

1. Girish mishra, yojana Sharma, kanishk Mehta, and gunjan patel - efficacy of distortion product oto-acoustic emission(OAE)/Auditory brainstem evoked response(ABR) protocols in universal neonatal hearing screening and detecting hearing loss in children $<2$ years of age. Indian $\mathrm{J}$ otolaryngol head neck surg. 2013 Apr; 65(2): 105-110.

2. Yojana Sharma, girish mishra, sushen $\mathrm{H}$ bhatt, somashekhar nimbalkar- Neonatal hearing screening programme (NHSP): at a rural based tertiary care centre. Indian journal of otolaryngology head and neck surgery (oct-dec 2015) 67(4):388-393.

3. Nagapoornima P, Ramesh .A, Srilakshmi, Suman Rao, Patricia. P.L. and Madhuri Gore. Universal Hearing Screening. Indian Journal of Paeditrics.2007 Jun;74(6): 545 $-9$

4. Paul A (2011) Early identification of hearing loss and centralized new born hearing screening facility- the cochin experience. Indian paediatrics volume 48(5):355-359.

5. John jewel, p.v. Varghese, tejinder singh, ashish Varghese - newborn hearing screening - experience at a tertiary hospital in northwest india. Int $\mathbf{J}$ otolaryngol head and neck surg 2:211-214. 
6. Year 2007 Position Statement: Principles and Guidelines for Early Hearing Detection and Intervention Programs. Pediatrics .Vol. 120 No. 4 October 2007, 898-921. 